\title{
Giving up on drugs: homeless young people and self-reported problematic drug use
}

BY DEBORAH KEYS, SHELLEY MALLETT, AND DOREEN ROSENTHAL

Numerous studies have revealed high levels of drug-taking among young people experiencing homelessness. This article draws upon 40 in-depth interviews carried out as part of a five-year longitudinal study of homeless young people (Project i). It is noteworthy that almost all of those who identified their drug use as problematic gave up or reduced their level of use without treatment or professional assistance during the period of the study.

The interviews provided insight into the way in which some young people experiencing homelessness view their drug use and the actions they take in light of these understandings. Here we report their stated reasons for giving up or reducing usage and identify some commonalities that may have impacted on the outcomes.

AUTHORS' NOTE: This research was carried out with the generous support of the National Institute of Mental Health (NIMH), grant number MH61185. Thank you to the participants whose stories have contributed to this article and the interviewers who gathered the stories.

(C) 2006 by Federal Legal Publications, Inc.

CDP SPRING 2006 issue article by: KEYS, et al. 
People typically regard Jamie as being "on the streets" but to him living in a bushland squat means he is "not quite homeless". In his words, he is "homeless but not roofless". Jamie is 17 and has been living on the streets on or off since he was 12 . His parents were abusive and Jamie has lived in foster care or with his grandmother for most of his life. After he left home, a friend taught him how to live by stealing cars, "doing burgs," and holding people up at knifepoint. He got into trouble over drugs with bikies when he was 12 -he says he didn't realize what he "was playing with". He started smoking marijuana at 11 and has used heroin a few times (his parents' drug of choice), ecstasy once, and also coke, speed and acid among other drugs. Speed is the only drug he has used at problematic levels.

"Oh, speed was ongoing. Speed, as soon as I experimented [with] it, I loved it, I wanted more and more, couldn't give it up, just wanted it. That bad, it destroyed quite a few of my relationships ... it's like you're in heaven mate ... ever since we were young I've been a violent person and ah, I snap quite easily, so it wasn't good stuff for me..."

He says "at that time it was either take drugs or kill myself". Jamie did hang himself a week before his first interview but was cut down by a friend. Over the last two years he has "woken up" and realizes that other people do care. He has given up crime and has a new girlfriend. He says looking after her makes him look after himself. He has also given up regular drug use apart from alcohol and marijuana which he believes help to control his anger. Occasionally, he will use other drugs recreationally. Now, he keeps himself safe by avoiding repeated use of any drug he particularly enjoys:

"I believe if I like a drug, not to touch it again because I will not stop. I've got a strong will power and if I want something I'll get it."

Jamie says that you need the will to survive. He'd like to believe he has that will but is not sure.

Estimates of drug use among homeless young people vary across studies but there is evidence of relatively high rates in 
this population compared to their home-based peers (Australian Institute of Health and Welfare (AIHW), 2002; Bailey et al., 1998; Blue Moon Research and Planning (BMR), 2000; Department of Human Services, 1998; Downing-Orr, 1996; Klee \& Reid, 1998; Kral et al., 1997; Miller \& Draper, 2001; Ringwalt et al., 1998; Rosenthal et al., 2004; Smart et al., 1994; Unger et al., 1998).

Debate exists in the research literature about the causal relation, if any, between drug use and homelessness. Some consider drug use as precipitating homelessness (Greenblatt \& Robertson, 1993; Noble, 1999). Others focus on drug use as a response to crisis and the ensuing instability associated with homelessness (Ayerst, 1999). Drug use is commonly perceived to be exacerbated through young people's contact with street-based or service-based homeless subcultures where drugs are more accessible. It is assumed that in these contexts newly homeless young people are highly vulnerable and likely to commence or increase their drug use in association with homeless peers (Whitbeck \& Hoyt, 1999). In discussing these findings, researchers and policy makers alike often presume that homelessness is ongoing, the influence of homeless peers is wholly negative and the possibility of avoiding long term problematic drug use is slight.

While there is research to indicate that drug use can be either a cause or a consequence of homelessness (Mallett et al., 2004 in press), there is little evidence about changes in drug use over time once young people become homeless. The following article addresses this issue. We report on the factors identified by young people as impacting on their drug use and the common developments in their lives that attended changes in that use. Our focus is on motivation and surrounding circumstances rather than technique. 


\section{Addiction and dependence}

The widely adopted medical model of drug use is based on the concept of addiction as a disease requiring professional intervention. It implies "once an addict always an addict", a stance that informs 12-step recovery programs. This position was challenged in the 1980 s by researchers such as Zinberg (1984) and Biernacki (1986) who dubbed it a myth. The importance of social context, in Zinberg's terms "set" and "setting" (Zinberg, 1984), to meanings and patterns of use has led to a greater focus on broader structural factors (Granfield \& Cloud, 1999; Moore, 2002; Waldorf, Reinarman \& Murphy, 1991). These approaches conceive of problematic drug and alcohol use as "dependence"-either as a change in state or a variation along a continuum (Moore, 1992) - rather than merely physical addiction.

Dependence has been variously defined. Burrows (1994) highlights a lack of control over usage and the emergence of physiological or psychological dependency. In contrast the Diagnostic and Statistical Manual of Mental Disorders (DSMIV) diagnosis of dependency emphasizes ongoing use (Coffey et al., 2002) among other criteria. Over time the focus of these definitions has changed away from the physiological (e.g. withdrawal) to the social (e.g. persistent desire or the existence of social consequences [Coffey et al., 2002]).

The shift from a notion of addiction to one of dependence has focused attention on social and cultural factors in the establishment, maintenance and cessation of drug use (Moore, 1992). However, as Moore has observed, the idea of dependence does not necessarily acknowledge that cultural, social, and economic factors can actually constitute and underpin, rather than merely influence, drug use. The idea of dependence can focus too heavily on individual deficiencies or proclivities, thereby overlooking the interaction between the broader context and the individual (Duckert, 1993).

CDP SPRING 2006 issue article by: KEYS, et al. 


\section{Giving up}

In recent years, more attention has been paid to those who cease problematic drug use without professional assistance or the aid of self-help groups. This is variously referred to as natural recovery, spontaneous recovery, remission, maturing out (Winick, 1962), autoremission, self-generated change (McCartney, 1996), or simply cessation (Waldorf, Reinarman \& Murphy, 1991). However, there is still relatively scant attention being paid to those who give up unassisted, despite the fact that change without intervention is widespread (Biernacki, 1986; Cunningham, 1999). Certainly, there has been no investigation of cessation or modification of problematic use among homeless young people.

Among those researchers who reject the medical model of addiction, there is agreement that multiple pathways out of problematic levels or patterns of use exist, other than through treatment (Blomqvist, 1996; Cunningham, 2000; KoskiJännes \& Turner, 1999; Sobell, Ellingstad \& Sobell, 2000; Waldorf \& Biernacki, 1981). Such pathways involve complex interactions between the individual and the world they inhabit.

For many, ceasing problematic drug use involves a cognitive evaluation of the pros and cons of continuing use, however others seem to simply drift out of using (Biernacki, 1986; Waldorf \& Biernacki, 1981; Waldorf, Reinarman \& Murphy, 1991). Those who actively quit and those whose use simply tapers off often report that they want to stop using because they no longer enjoy that particular drug (McCartney, 1996; Waldorf, Reinarman \& Murphy, 1991).

Although some studies have shown that most drug use tapers off by the early 30's (Chen \& Kandel, 1995), the relation between individual decision-making and social/environmental factors is unclear (McCartney, 1996). Commonly identified

CDP SPRING 2006 issue article by: KEYS, et al. 
social/environmental factors include health, legal, financial and relationship issues, meaningful work, and family/peer support (Bammer \& Weekes, 1994; Biernacki, 1986; Blomqvist, 1996; Brady 1993; Cunningham, Koski-Jännes \& Toneatto, 1999; Koski-Jännes \& Turner, 1999; Sobell, Ellingstad \& Sobell, 2000; Waldorf \& Biernacki, 1981; Waldorf, Reinarman \& Murphy, 1991).

Dealing with problematic drug use can prove challenging under the best of circumstances but there are additional hurdles for those who are homeless. Some imply that it is unstable housing (Henkel, 1999) that is a critical risk factor; others emphasize the positive aspects of good social relationships (Bammer \& Weekes, 1994; Granfield \& Cloud, 1999), and financial and employment security (Raynor, 2003). In this study we consider young people's accounts of giving up their self-reported problematic drug use. We identify those social/environmental and personal factors that young people highlight as pivotal to their reduction in drug use.

\section{Method}

This article is based on 40 semi-structured, qualitative interviews undertaken in Melbourne, Australia as a component of Project i, a five-year study of homeless young people in Melbourne and Los Angeles, California. ${ }^{1}$ In Melbourne, 674 young people, aged between 12 and 20, were recruited from youth and homeless services across metropolitan Melbourne between December 2000 and August 2002. Of these, 165 newly homeless young people were recruited to participate in the two year longitudinal component of the study. ${ }^{2}$

Newly homeless were defined as those who had been out of home from two days to six months at the time of their

CDP SPRING 2006 issue article by: KEYS, et al. 
baseline interview. This group included young people without any accommodation, those in emergency accommodation, temporary accommodation, and supported accommodation.

In-depth, semi-structured interviews were undertaken with a subgroup $(n=40)$ of those participating in the longitudinal study. These interviews were conducted 18 months after young people had completed their initial baseline interviews. The primary principles of selection for participation in the indepth interviews were gender, age, and level of service use. The sample was selected by generating eight groups of newly homeless young people from a cross-tabulation of age, gender, and service use (high and low).

Age was defined by median split (12-16 years and 17-20 years). For each participant, a measure of number of services used was created by summing responses to 18 service use questions on the initial baseline survey. High/low service use was defined by median split (0-2 and 3-9 services used). Five participants from each group were then randomly selected to undertake the interviews.

Following institutional ethics approval, interviews lasting between 1 and $11 / 2$ hours were undertaken by trained interviewers between November 2002 and August 2003. Interviews were conducted at the referral agency or at the research center. Informed consent was obtained and the interviews were tape recorded and later transcribed. All young people received $\$ 40$ (local currency) compensation for their participation.

During the interviews young people were asked about their experiences since they first left home, the places they had lived, the people that support them, their drug use, sex life, their education, and the ways they get by. They were also asked about their health and how their experience of homelessness may have changed their lives.

CDP SPRING 2006 issue article by: KEYS, et al. 
Narrative and thematic analysis was employed to analyze the data. The data reported in this article were drawn from these 40 follow-up interviews undertaken at 18 months from baseline. Initially, thematic analysis was carried out in relation to a number of themes including basic demographics, living arrangements, employment, and education. For the purposes of this article, young people's homelessness and drug use narratives were explored. In this analysis we focused on their stories of change in relation to drug use. ${ }^{3}$

\section{Results and discussion}

Young people's drug taking does not follow a single trajectory. While this is unsurprising in itself given the broad literature on young people's drug use, it does disturb common preconceptions about homeless youth and drug use. While we tend to suppose that most young people who experience homelessness are likely to be expanding their drug use, in fact many were reducing it either while homeless or in the period following an episode of homelessness. Our data provides a picture of the drug use of the 40 participants at 18 months from recruitment and reports on their reflective narratives of changes in their patterns of usage.

The 40 in-depth interviews do not constitute a representative sample but they do provide insight into the way in which some young people who experience homelessness view their drug use and the actions they take in light of these understandings.

Interestingly, of the 40 interviewed, 21 young people either claimed they were not using, had not used, had used only once or twice over 18 months or did not consider their use significant enough to mention. Nineteen told us that they were using drugs or had used drugs more than once or twice at some time during the last 18 months. Given our interest in homeless young people's patterns of self-reported drug use 
over time, we focus on this set of 19 young people. We report their stated reasons for changed patterns of usage and identify some common circumstances that may have impacted on the outcomes.

Patterns of drug use varied, with reported increases and decreases both prior and subsequent to leaving home. Some took up using particular drugs after becoming homeless while others had used for extended periods while living at home. Out of the 19, a surprising number reported that they had reduced their drug usage, with 13 giving up one or more drugs and a further four cutting back their level of use. In total, 17 out of 19 had dealt with their self-defined drug problems by the time of their 18 month interview. Only one of the 17 was still in the process of overcoming problematic (in this case, heroin) use. Details of young people's drug use are included in the Appendix.

Overwhelmingly, marijuana was the most commonly used drug and the drug young people most often identified as causing them problems. Ten young people reported giving up marijuana entirely, while two others cut back on usage. Of the ten who gave up, one also stopped abusing alcohol and another gave up speed and ecstasy. One who gave up smoking marijuana also ceased occasional use of speed and "mushrooms". However, one who stopped smoking marijuana took his first acid trip a couple of weeks prior to his most recent interview. Five stopped using speed, although one of these reported giving up speed a year ago and drinking (earlier), but in the week prior to her interview had taken speed again and used ecstasy for the first time. One ceased ecstasy use (which had been frequent) altogether, another cut back from weekly to bi-annual use and two others stopped their occasional use. Another had successfully given up heroin two years earlier, then methadone, and finally speed six months ago. One young woman had moved from daily to occasional heroin use, but was finding this a struggle. One young man had ceased his occasional heroin use.

CDP SPRING 2006 issue article by: KEYS, et al. 
Young people often used more than one drug regularly; those giving up one drug were in some cases still using others. Of the 17 who had given up problematic ${ }^{4}$ drug use, six continued to use other drugs in ways they considered manageable and safe. Usually this involved occasional or experimental usage, though for a few it meant using drugs they believed did not have any adverse effect (usually marijuana) regularly in moderation.

For example, one 17-year-old said he did speed, coke, pills, and marijuana, but gave up taking pills each morning because they were "fucking him up". However, he continued to use drugs when clubbing with friends. In another attempt to keep within boundaries he considered safe, he only bought speed in rock form, commenting that "the crap that they cut speed with can kill you".

Of the two who did not reduce use at all, one young woman, Kim, already maintained a safe level of usage.

"I usually smoke about twice a week 'cause like if you're smoking it everyday, you just don't get the effect anymore and then you get this feeling of moving onto higher drugs that's what everybody says anyway. So I'd rather just smoke it every now and then so you get the same effect. (I: Yep, yep, and have you seen other people around you do that, like go onto higher things) Yeah, I have actually like soon as they don't get the feeling they used [to from] weed. [They go on to] speed and then heroin and everyone thinks I'm gonna do that, nuh, I hate needles - no ..." (Kim 17 years)

Ben, who identified his drug and alcohol use as problematic but had not cut back, said he had trouble reconciling partying and work responsibilities. He described himself as some one who should be using his brain but who has "just been on pause for a bloody long time." (Ben 19 years)

Drinking alcohol was seen quite differently from using illicit drugs. A couple of those interviewed who had given up drugs spoke of drinking socially but as they were not asked directly whether they drunk alcohol, others may have not thought

CDP SPRING 2006 issue article by: KEYS, et al. 
their drinking worthy of a mention. For this reason the numbers drinking at levels that may be causing health and social problems may be greater than the interviews indicate. As mentioned above, two said they had experienced a problem with alcohol use but had either given up of modified their drinking. Only one young person intimated that he continued to drink too much.

\section{Identifying problematic use}

Recognition that drugs are having a negative effect is a precursor to deciding to stop or reduce usage. One report, commissioned by the Department of Human Services, Victoria, Young people and drugs: Needs analysis (1998) states that many young people do not regard their drug use as a problem but the majority of those in our study who had used regularly, while not presenting to agencies with a drug problem they wanted to solve, certainly identified particular levels or patterns of usage as problematic. Problematic use was associated with three aspects: A need for that drug in order to get through the day; drug use dominating daily life at the expense of other activities; unpleasant physical and psychological effects. All of these had negative social repercussions. Dependence, drug use dominating and negative effects all constitute "pushes" for homeless young people, but those interviewed were also subject to "pulls", most often a desire to "move on". It was in response to some, or all, of the aspects listed above that individuals identified their drug use as problematic and in all but one case made attempts to control their usage of the particular drug they saw as being connected to these effects.

Dependence Although it has been suggested (Department of Human Services, 1998) that young people are more likely to abuse rather than depend upon drugs, some of the young people we interviewed claimed they experienced a level of chemical or psychological dependency. While acknowledging the

CDP SPRING 2006 issue article by: KEYS, et al. 
different perspectives on dependence-as a change in state or a continuum - outlined by Moore (1992), we do not enter the debate here. Rather we use the term to convey the sense of necessity/compulsion to use drugs reported by some of those interviewed. Although the ideas of dependency and drug use dominating daily life are closely associated, young people spoke of these in slightly different ways. When they spoke of dependence they emphasized a compulsion to use, while comments about drug use dominating focused on the consequences of acting on that compulsion. Here young people report on their feelings of dependence. All subsequent quotes relate to marijuana use, unless otherwise specified.

"I'd get up in the morning and I was doing laboring work or something and have a pill in the morning to keep me going, so it became a bit serious. [ . . . ] I just decided "well fuck this" it was fucking me up too much [pause 2 secs] I'm gonna stop so I did." (Tim 17 years)

"I was doing good at school, but then drugs took over and now it's all I want." (Nick 17 years)

"I thought I found a really good friendship in this person and um, I thought, oh, yeah, I'll try it, it won't hurt but um-and then you slowly get addicted to it and your body gets really dependent on it and it's really hard to say no." (Kayla 17 years, gave up speed and cutting back heroin use)

Drug use A number of those interviewed, stressed how all other dominating activities fell by the wayside as drug taking or getting money for drugs became their prime activities. Some mentioned missing other pursuits, like playing a musical instrument, painting, drawing, or writing. Others also expressed the opinion that their lives had become routine and boring.

"And also when you smoke marijuana it becomes part of you and like really part of you, like that's who you are, you're a marijuana smoker, you're always thinking that way, you need it each day and like, that's why so many marijuana smokers are alike, and I fitted into that crowd and I wanted to do more of that, but now, like I'm back to where I started." (Phoebe 19 years)

CDP SPRING 2006 issue article by: KEYS, et al.

07-03-2006 Rev 
"On average I was probably smoking about two grams a day I couldn't really say how many times, it was just a lot ... It was mostly in the evening. I wasn't doing anything during the day at that time, I wasn't at school or anything and I wasn't working-I mean I was at school, I just wasn't going so, yeah, just slept all day and I'd wake up about two o'clock and go ... it was like a routine and it just got worse and worse." (Lauren 19 years)

Negative Four young people reported that marijuana caused paranoia physical, and another said it made him sad. A number stressed the emotional and mental effects impact of drug use on their mental capacities, saying it impeded memory and inability to concentrate or perform mathematical equations or even form words into sentences. One young person said that using drugs (ecstasy, speed, and marijuana) exacerbated his depression. Other physical effects included being unable to feel their limbs and "coughing up black shit".

"It was to the point where I was getting scared of walking onto busy trains. I remember I used to miss trains "cause I was just that paranoid and it was full on." (Kate 16 years)

"I was smoking what two, three grams a day you know, like that was pretty heavy, you know like, I just cut down because I was going on the skids and I - my mind was getting too scattered. I didn't even - like I felt I wasn't even alive, you know, I'm like the walking dead ..." (Nick 17 years)

"It [heroin] used to make me feel like I could do anything it, it used to put a lot of confidence in me and now it just makes me feel like shit, and I hate it when people who love me see me like that . . . I can't use it any more because like in the last three or four months I've asked dropped [overdosed] six times and it's been pretty damn serious last time. "(Kayla 17 years)

Two young women said that the overdose of a friend or acquaintance had affected their attitude to drugs. Although these incidents had a significant impact, they did not result in either of the young women giving up drugs completely at that time.

CDP SPRING 2006 issue article by: KEYS, et al. 
"[I went out with] a chick that lived at the refuge [ . . ] one night and I came home and she stayed out and the next day a fella rang up and said "oh, she died last night" and it's like "oh my God" just, just crazy and then I moved back to Mildura with my adoptive parents, "cause I just wanted to go "oh fuck this, I've had enough". (Emma 19 years, gave up heroin, methadone, and speed)

Emma fled the refuge, an environment she had found very supportive, and returned to a period of heavy amphetamine use before finally giving up.

A number of young people stressed that they loved the drug experience but not the negative consequences of using. One explained how ecstasy enhanced his friendship.

"Last year, when I met my best friend, we used like a lot of ecstasy, and ecstasy makes you really close, it makes you bond with people ... And me and my mate now, we're still best friends, it's just that we're like, we don't go out that much to clubs together and don't take drugs. But we're still best friends, we're still close because we've done so much in the past." (Adam 18 years, gave up marijuana, speed, and ecstasy)

Moving on Closely aligned to the concern about drug use dominating their lives was the commonly expressed opinion that using was also no longer fulfilling. Six of those who gave up explicitly identified a desire to move on in their lives and regarded their drug use as holding them back. One said that his main motivation to stop smoking marijuana was financial:

"I was wasting - I probably spent thirty grand on it I'd say in the last three years, yeah, and that's all the money I've got-earned through my apprenticeship and I've got nothing to show for it, only a couple of guitars." (Damon 19 years)

Three stated that they were bored or sick of using. In some accounts individuals expressed the opinion that there was no point to a social life that consisted of sitting around smoking with the same people. Others intimated that they were ready to take steps towards the future and that their current situation was akin to treading water.

CDP SPRING 2006 issue article by: KEYS, et al. 


\begin{abstract}
"Back then there were things I could do to make myself happy and I always smoked marijuana, go to friends' houses and smoke marijuana and like that sort of stuff, that was my social sort of [life] then and now it's like, well I can't do that, I can't base my life on that ..." (Phoebe 19 years)

"Me and a couple of mates just used to sit at another dude's house every Friday, Saturday night, just smoke and thought what's the point of this um, sitting down smoking [?] not worth it, "cause I did that at home ..." (Sam 15 years)

"Just sort of basically trying to-trying to be good, you know, like I've sort of done some pretty crazy things in the last couple of years and sort of straightened out now, just trying to be normal and um, (I: So what's good and normal for you? What does that mean?) Alright, whoa, you're not going out and doing illegal things for a start like I've been in a bit of trouble with the coppers and-you know, not taking any drugs and just sort of being sensible person, you know, I'm 20 years old, I've gotta sort of become an adult some time in your life so, try, try and do it." (Emma 19 years, gave up heroin, methadone, and speed)
\end{abstract}

Services and Very few young people connected their decision to quit or the giving up actual change in their levels of drug use to contact with services, either drug and alcohol specific or generalist. This accords with studies by Brown (1991) and Di Mascola (1993) and a study of substance use among adults (18 and above) in adult crisis accommodation services in Melbourne (Raynor, 2003) that found that homeless people, including homeless young adults, rarely access specialist drug services. It is also in accord with Prochaska and Di Clemente's (1986) suggestion that the vast majority of young people will change their addictive behavior without intervention or formal treatment. They observed that it is not known which young people have the capacity to change without assistance. While our research cannot provide this information, the level of concordance in the stories of the young people who did change on their own does suggest some possible contextual factors.

In the preceding 21 months only five young people sought assistance for what they perceived as their drug problems, and

CDP SPRING 2006 issue article by: KEYS, et al.

07-03-2006 Rev 
of these only three went to detox. Of the five, only two reported being satisfied with the help they sought. Indeed, one "dissatisfied client" sought help only at his mother's insistence and had no intention of giving up his heavy marijuana use. In the long term, four of the five gave up the drugs that they identified as being a problem, and one cut back usage but only one did so with professional help. The others either gave up well after receiving assistance or did not attribute giving up to the help they received. Prochaska and Di Clemente's (1986) suggestion that most young people will change on their own without the help of any formal treatment program would appear to apply for the young people in our study. Most stated simply that they decided to give up and did so.

“Um, I don't really know, 'cause, you know, I've been trying to quit for awhile but it was pretty hard, so I ended up just saying, yeah, the last smoke about New Year." (Sam 15 years)

While some research suggests that entry into services for the purpose of dealing with substance abuse increases with age (Department of Human Services, 1998), age did not appear to be a factor in relation to giving up without assistance from drug and alcohol services or workers. Those who dealt with their problems with drugs ranged evenly across the 15 to 19 year-old age bracket. This was considerably younger than has been reported elsewhere. Chen and Kandel (1995) in their study of drug use by adolescents to those in their mid-thirties found that marijuana use peaked in mid to late adolescence and declined among those aged 23 to 24 .

Very few of the young people we interviewed accessed drug and alcohol services, although many of the 19 used mainstream services. Pressing concerns such as the need for housing and income, rather than a desire to deal with drug abuse or dependence, usually prompted these contacts. As reported elsewhere the issues which accompany drug use may take precedence (Department of Human Services, 1998). Two of the nine had only used Centrelink (a government income support agency) and a third had visited Centrelink and a

CDP SPRING 2006 issue article by: KEYS, et al. 
psychologist. While we cannot draw any conclusions regarding a link between service use and giving up problematic drug use, what we can say is that the remaining six all had contact with more than one generalist service and overall these contacts, with the exception of those with Centrelink and DHS (Department of Human Services), were predominantly positive. Although our participants were selected on the basis of high or low service use at the outset of the study, changed patterns of service use during the intervening period rendered this categorical distinction irrelevant.

The role of generalist services in facilitating young people giving up or reducing drug or alcohol abuse is unclear. It is possible that these services may have assisted young people to modify problematic use. However, acknowledgement of such a link was rarely identified by the young people themselves. One young person, who had given up heroin just prior to her first interview with Project i, and methadone and speed since then, explicitly connected acceptance from a worker with improved self-confidence.

"[going to refuge] ... it helps build confidence, you know, just made me realize that just because I'd used drugs it didn't mean I was the scum of the earth and that was something that sort of people had always made me think I was ..." (Emma 19 years)

However, Emma made the point that she got herself out of her dependency:

"I want to get into a sort of job one day, like as a career where, you know, I'll help young people like youths with drug problems and things like that, just because I've been there, I've done it and in a sense I've sort of got myself out of it by myself, you know like I got off the methadone by myself." (Emma 19 years)

It could be that positive relationships with workers may lead young people to feel happier about themselves and their lives in general. This may place them in a good position to address problematic drug use. First, they may no longer need drugs to

CDP SPRING 2006 issue article by: KEYS, et al. 
mask emotional pain and secondly, they may feel stronger and more confident in their ability to shape their lives.

\section{Changing contexts}

In a study of narratives detailing recovery from addictive behaviors, Hänninen \& Koski-Jännes (1999: 1847) found that despite considerable variation they all described a change in relationships. They suggest that "addictive behaviors may stem from various fundamental problems in human relationships". Our findings do not conclusively support or contest this statement, however improved relationships featured in the narratives of the young people in our study who have experienced homelessness and modified their drug use.

Young people often spoke of their drug use in terms of their relationships with others. Most commonly, partners and friends were seen as playing a role in their patterns of drug use. Cultures of drug use among groups of friends and established practices shared by couples were the most obvious forms in which relationships impacted on use. Whether or not the young person had a supportive partner or friend may have had a less direct, though nevertheless important influence. Relationships with family members and, to a lesser extent with workers in agencies, were also mentioned. In a number of cases, drug use could be seen as more broadly episodic, connected not only to relationships but also to other life events, a matter we take up after looking at the importance of relationships.

Partners Nine of the 17 who dealt with their problematic use had supportive partners. This finding is as odds with Ennett et al. (1999) U.S. study of 14 to 21 year old homeless youth that found having a sexual partner in your social network increased risk of substance abuse. Four young women, all of whom gave up heavy marijuana use, and another who was trying to come off heroin were effusive in their praise for

CDP SPRING 2006 issue article by: KEYS, et al. 
their boyfriends. One described herself and her boyfriend as being totally obsessed and in love with each other, and another said that she could trust her boyfriend with her life. A third described her partner as very caring. Sixteen year-old Kate's response (below) clearly makes a connection between being loved and giving up.

"Just being there and the things he says, and the fact that he loves me in the first place is just like 'wow, someone likes me' it's just, yeah, something to live for in a way." (Kate 16 years)

The young woman who was struggling with heroin dependence reported:

"When I'm by myself, when I feel like nobody loves me and that nobody cares about me, I feel so vulnerable and that's when I end up throwing myself back into drugs ..." (Kayla 17 years)

Her recent success with cutting back use coincided with becoming involved with a supportive partner.

"He's caring, he's really supportive and he doesn't say the wrong things. He doesn't hurt me at all he's just-he's there all the time and he's at me, making sure I go to my appointments, picks me up." (Kayla 17 years)

A number of those who gave up talked about how giving up was related in some way to the nature of their relationship with a partner, in particular whether or not their partners were using.

"I cut down with the dope because I wasn't living with Nick . .." (Kate 16 years)

"I stopped when I met Tim like I just - 'cause I just, I don't know, I just woke up and I thought I don't want to look like an idiot ..." (Eva 16 years)

Friends The young people interviewed also associated problematic and scenes levels of drug use with certain groups of friends and a few mentioned the need to break away and form new networks of friends. Several young people mentioned that their relationships with friends revolved around drug use. Social networks based 
on drug use may in some circumstances be considered to be communities of interest, or in other cases they may be simply communities of circumstance, terms coined by Dowsett \& Davis (1998). When users and workers have a sense of themselves as a group with shared concerns and goals - say legalization - they are bonded by shared interests and can be regarded as communities of interest. At other times, small social networks which use together may have little in common other than their drugs of choice, a circumstance that may bring disparate individuals into close contact but not necessarily result in a group that feels a sense of common purpose or impetus to political action. In these situations they may be more productively regarded as communities of circumstance. As Moore (in press 2006) has noted, the common evocation of "subculture" in reference to networks of recreational users can occlude the existence of multiple and competing discourses, implying greater homogeneity than exists. Our point here is that the existence of a community or subculture among users as a group or even among smaller networks should not be assumed. This is particularly true of homeless young people, where it is far from clear that they develop fixed subcultures (Mallett et al., 2004). Moore's preferred term "scene" is more useful in that it recognizes that the milieu and the relationships within particular social groupings play a part in young people's patterns of use, while being more local and specific and rejecting the coherence and strictly bounded associations of subculture.

The young people whose stories are presented here are a diverse group, they came from different socio-economic backgrounds, lived in different social environments, and their reasons for using the drugs they used, and their "ways of using" (Sharp et al., 1991) varied greatly. Some saw their drug use as an expression of their "alternative" identity while others used to make life tolerable. Although many participants talked about using with particular groups of friends or in particular "scenes", they did not suggest peer pressure was an issue.

CDP SPRING 2006 issue article by: KEYS, et al. 
“Also I'd stay at mates [ . . . ] I'd just think they were the best because we were getting that stoned at nights and that smoked a lot in the morning to get it out of your system, you'd have a big cone ..." (Sam 15 years)

When it came to giving up, friends who used were sometimes seen as positive assets who assisted quitting and sometimes as negative "role models" who put young people off using.

"Like most of my friends now still do drugs, like, full on into drugs. And I've had friends that like, you know, deal, and then they stop dealing for after how long, years And like, they'll pretty much be dealers and then they stopped and that was it. [ . . . ] Yeah like, I thought to myself now I'm hanging out with the wrong crowd. Like even though some of them were really close friends of mine, I had to sometimes choose the crowd I was hanging around with. And like not avoid them, but like not see them as much you know. And um, yeah I had to change, like, I knew drugs would effect my schooling as well." (Adam 18 years)

Sam, whose quote above captures how smoking can be a dominant activity in a circle of friends was able to quit easily when he and his friends decided to all give up together.

"I tried before but, you know, it was bloody hard, but I found this time that it was easy I don't know, it was just I think, all my mates were quitting at the same time as well ..." (Sam 15 years)

While a couple of young women stressed the different quality of friendship with nonusers once they had ceased or modified heroin use, another, referring to meeting people after taking speed and ecstasy did not make this differentiation.

"Well the people who were my friends who I would now call - that were associates - you know, I thought they were friends [ . . . ] now the people that I hang around with, they are actually friends, I know they care [... ] and that's the big difference." (Emma 19 years)

"I think it's fun, like, I don't know, when I get high it's really good, I just-I don't know, I can just let loose, I can meet people better like really easy like I think Friday night I made about twenty new friends." (Caitlin 18 years)

CDP SPRING 2006 issue article by: KEYS, et al. 
Families Like partners and friends, families both hindered and helped giving up. Overall, Ennett et al. (1999) found that being in close contact with a family member decreased the likelihood of illicit drug use. Some of those we interviewed were severely hindered by their parents' own drug use.

"I mean if my mother was still around I don't think I'd be with my boyfriend right now, and I've been living [here] for two and a bit years, so that definitely wouldn't have been, um, I would have to say I would probably still be smoking, 'cause I used to smoke bongs with my mum when I was only thirteen years old and so forth, so I would definitely still be smoking 'cause it was around me." (Imogen 17 years)

"Mum used to give it [heroin] to me and shit like that you know, when I was sort of -I was on the methadone, trying to get off of it you know, working as a waitress in St. Kilda you know, like "fuck" and "phew, how's that?". (Emma 19 years)

Two-thirds of those who gave up reported improved relationships, to some degree, with their families. It is not always clear whether the relationships improved before or after they gave up. In some cases they may have given up after their relationships improved but in others giving up may have preceded the improved relationship. Where drug use was an issue in the family conflict that tipped them into homelessness, giving up may have paved the way for an improved relationship. It may be that neither is causally related to the other in any simple way. Both may be the result of young people growing up and reassessing various aspects of their lives, including, in relation to family, working out ways to avoid conflict. Indeed, three young people stated that they had re-evaluated their past and with hindsight saw that they shared some responsibility in precipitating or exacerbating the situation that led to their becoming homeless. This is not to say that they necessarily forgave parents' behavior and certainly not that they blamed themselves for what were generally complex and often abusive situations. The following quotes illustrate a variety of experiences of improved relationships and also show the

CDP SPRING 2006 issue article by: KEYS, et al.

07-03-2006 Rev 
complexity of young people's lives - a complexity that makes drawing any straightforward conclusions about cause and effect impossible.

Caitlin said she had "cleaned herself up" and now her mother is:

“. . . a lot more understanding now like I think "cause I'm older and I've kind of proved that I can be a normal person as in her eyes. She kind of -I don't know, she kinda trusts me a lot more like she believes me when I say I'm going here or whatever, you know so there's a lot more trust and like I just-I don't know, I just communicate with her heaps better than when I used to. Um, we don't really ever fight any more, like, just sometimes like she'll say something and instead of, you know [pause 2 secs] I'll kinda be the adult I suppose in that way, like I won't say something back, I'll just leave, like I'll just go home so it saves starting an argument." (Caitlin 18 years)

In the following case, giving up marijuana appears at first to be unrelated to the improved relationship. However, Eva said that she chose to move out of home because of family conflict and it is therefore her responsibility to "grow up quicker" - to not go running around the streets or out to nightclubs all the time. It may be that Eva's "growing up", of which giving up drugs was a part, contributed to Eva's mother's positive response.

"I just thought it was like when I found out I was pregnant, it wouldn't be fair that the baby wouldn't have a grandma like'cause our differences aren't anything to do with him, do you know what I mean? . . . and I said to Mum "we do have differences, but I think we need to sort them out because we're gonna-if one of us dies, like if something happened", I know it sounds stupid, but like I could die before her [laughs] and "like if anything does happen to one of us the other is gonna regret it, not talking to each other", yeah. ... She said "yeah"- like we're close now like we're alright now so she responded pretty good." (Eva 16 years)

Stability In addition to positive changes in relationships, particularly improved relationships with parents and the advent of new relationships with supportive partners, those who reduced or

CDP SPRING 2006 issue article by: KEYS, et al. 
gave up abusing drugs also generally reported that they had moved out of the negative environment that they had inhabited, or just left, at the time of their initial interview. When first interviewed they were newly homeless having left difficult and often conflict ridden family situations. Eighteen months later, 13 of the 17 were no longer living in the negative situations, either because family conflict had been resolved or because they had moved on to other accommodation. Twelve were in what they regarded as stable accommodation, as was the thirteenth until losing her job. It would seem that stability across the board was a feature of the lives of those who had dealt with their problematic drug use. Both temporal and spatial distance from the situation prior to homelessness, the crisis point of leaving and the instability of the period that followed may contribute to the young people's success in giving up.

Entering another life phase can prompt people to take stock of their lives, now and in the future, a situation which can lead to them deciding to make changes (Department of Human Services, 1998). As we have mentioned earlier, some young people had re-assessed their lives and saw things differently to the way they had 18 months earlier. Those who spoke of moving on and becoming adults certainly saw giving up substance abuse as a part of this process. Two young people who gave up were about to become parents - a very pressing situation requiring considerable re-evaluation and indeed change if they were to parent effectively.

Given that drug usage often changes when situations change it is in a sense not surprising that those who dealt with problematic levels of use also experienced improvements in a number of areas of their lives, including those noted in other studies. Most importantly, the majority had moved out of homelessness into more stable accommodation. 


\section{The episodic nature of use}

While some narratives, as told, went from a realization that there was a problem, to a decision to give up the problematic drug and the enacting of that decision, others were less straight forward. Drug use rose and fell in concert with various events in the young people's lives. The importance of the social processes of social context to drug use noted by others (McCartney, 1996; Moore, 1992) was evident in the stories young people told. As we have seen, relationships played a significant role in this fluctuation. One factor, which was a component of positive relationships, but also appeared to have an influence more broadly was stability. The less stable the accommodation environment, the more likely it is that a problematic drug use pattern may develop (Bessant et al., 2002). Although the numbers are small, our study suggests that moving away from instability (in relationships, housing, or both) may play a role in the reduction or cessation of drug use.

Caitlin's story provides an example of the way in which one event, in this case losing her job, can lead to problems, such as difficulty paying rent and the subsequent possibility of her losing her housing, which in turn lead to further problems. For Caitlin, the ramifications of unemployment reverberate throughout many aspects of her life. Her improved relationship with her mother, which she attributes to her proving to her mother that she can be "a normal person" is now under pressure. Caitlin has become financially dependent upon her mother for rental payments, a situation that cannot be sustained due to her mother's own financial situation. Caitlin described how things had changed since she lost her job:

"I got away from it all. I got a job and I just really cleaned myself up and then, like, me and Mum were really good friends I suppose you could say, like we got along really good and now I've left home again-like we still get along good, but now, it's just hard between us because I can't support myself at the moment." (Caitlin 18 years)

CDP SPRING 2006 issue article by: KEYS, et al. 
"My Mum's supposed to be getting remarried and she was helping me out with rent and stuff because I lost my job and now she can't get married 'cause she's like hasn't got any money left and everything and I can't move in with her 'cause she's got no room at her house and - 'cause I don't like have a job and stuff I can't-like I'm gonna have to-like I can't pay my rent or anything and I don't know, it's just really hard 'cause now-Mum's like [pause 2 secs] my Mum's not taking it out or anything on me, but she's kinda getting angry 'cause I can't get a job you know, like, she's saying I can't afford to help you out any more and stuff, but like-I don't know, 'cause she's, she's in like heaps of debt now and stuff like that and I don't know, I just can't seem to get on my feet at the moment. Like 'cause I've borrowed heaps of money off friends, so now I'm in debt as well, like with my friends and stuff and I don't know, everything's just going wrong."

Caitlin described how she got back into drug taking, using amphetamines again and ecstasy for the first time, during the weekend prior to her most recent interview.

"We took drugs and everything to get high so we could stay awake I suppose 'cause we went to raves and everything like I don't usuallylike I don't-I never-like I stopped doing that sort of stuff when I was working, "cause I was tired from work but now like I'm not working and it's just "who cares" [ . . . ] and now "cause I'm not working and like I've been-everything's going downhill at the moment so, I just kinda of feel like if I go out and I can just enjoy myself, like I just don't seem to care at the moment..." (Caitlin 18 years)

Caitlin says she would like to be working because:

"When I'm not working, I do things I shouldn't do [ . . ] 'cause I just think "I'm bored, let's do something" but 'cause I don't have a job or anything like that it's kind of hard to go change your life around."

\section{Reflections on giving up}

Young people who have cut back on problematic usage or given up entirely generally reported positive physical and mental effects, for example, more energy, less paranoia, greater self-confidence, and improved memory. A couple said they were going out more and meeting new people, a

CDP SPRING 2006 issue article by: KEYS, et al. 
situation they attributed to feeling better generally. Closely aligned to this is the often stated need to make new friends if their old friends were still using. One young woman mentioned that she felt ready to reconnect with old friends she knew before getting into drugs now she had given up.

"I've lost contact with a lot of them but I feel now that I've stopped smoking pot and stopped, you know, just being stupid I can go back to them and say "here's who I am now, I've progressed. I'm not still stuck in that hole that I was in", yeah." (Phoebe 19 years)

"I've smoked twice since I've given up but, yeah, I feel a lot healthier. More energy [ . . . ] not even tired yeah [ . . . ] you know I can be bothered doing more things now just not sitting at home and smoking the bongs $[\ldots]$ Going out more $[\ldots]$ meet more people, yeah." (Sam 15 years)

Some, including those who identified positive changes, also reported ongoing negative physical effects.

"I made that mistake, you know but - and I'd-I'd tell everyone that I know that doesn't smoke, you know, I kept telling 'em, don't start smoking man, you know it's not good for ya, you know, I'd be twice as smart as I am, I'd be so much healthier or have a better body, you know like, it's not good. [ . . . ] I have trouble putting words into sentences and like speaking and maths, you know, "cause I was really good at maths some time ago ..." (Nick 17 years)

One young woman related how giving up marijuana meant she needed to face and deal with emotions she had previously been able to block out.

"I pretty much smoked to numb that feeling as well that's why in the last six months as well, since I stopped, I had to go back to that whole emotional, you know. Yep, I've had to deal with stuff I've numbed for so long, yeah." (Phoebe 19 years)

For another young person, drugs masked a reality he now experiences as unpleasant.

"Everything - just seems everything, seems like bullshit when I'm straight . . . People seemed a lot nicer people just - the bullshit didn't seem to be there ... I don't like seeing the crap [but] I don't really want to go back and not see it, it's kind of like telling myself that it's not there." (Craig 18 years)

CDP SPRING 2006 issue article by: KEYS, et al. 


\section{Conclusion}

Rather than increasing drug use over time, many young people who had experienced homelessness reduced, if not gave up, their problematic drug use. This is an unexpected finding given commonly held assumptions about the impact of the homeless lifestyle on drug use. For this sample at least, patterns of drug use were similar to those described for their home-based peers. For both groups, marijuana is the drug of choice and modification of use is likely to be unaided by professional drug and alcohol specific treatment services. While young people sometimes referred to physiological consequences of their drug use they did not usually equate this with a chemical dependency. The way in which they dealt with their problematic use reflects this understanding and adds weight to arguments that highlight social and interpersonal rather than physiological/medical interpretations of problematic drug use. The stories told by these young men and women support Moore's conclusion that the concept of drug dependence must incorporate not only social, cultural and economic context but also the social processes occurring within such contexts (Moore, 1992).

A strong finding was that the lives of young people who had given up or controlled their problematic drug use had improved dramatically since their entry into this study 18 months previously. These young people reported positive changes in four areas of their lives. Two involved relationships-having a supportive partner and/or experiencing improved relationships with family members, particularly parents. The third positive change involved relationships and accommodation - who they were living with and where. The last change was associated with a move to more stable accommodation. Employment also appears to be associated with positive outcomes, but we are unable to infer a clear association between this and a reduction in drug use. See Appendix for details of life circumstances and changes.

CDP SPRING 2006 issue article by: KEYS, et al. 
Those who dealt with their drug issues came from the group identified as having predominantly positive accounts of their lives. Of the 17 young people who had reduced or stopped problematic drug use, four reported improvements in all four areas, four in three of the areas, six in two areas and three in only one area. Those who had experienced positive change in only one or two areas included Caitlin and Tim. Caitlin had experienced improvements at the time she gave up using speed but at the time of the interview was using again and described things as "going downhill" and Tim, who despite giving up daily pill use, continued to use a number of drugs socially. The two participants, Ben and Kim, who had not changed their levels of use had experienced change in only one area.

Clearly there is an association between positive life changes and reduction in drug use for this population that is not simply confined to changes in homelessness status. Our findings indicate that stable and supportive relationships, particularly with partners, are also extremely important. A number of young women directly linked giving up drug use with having a loving and supportive partner whom they could trust. Similarly, improved relationships with parents went hand in hand with giving up. It could be that as young people change their lives, parents are more receptive to opening communication or resolving or putting aside past conflicts.

Our findings raise many questions about current drug and alcohol treatment responses for homeless young people. The fact that the young people in our sample used specific drug and alcohol services infrequently invites questions about the scope, setting and timing of drug and alcohol treatment services for this population.

While the young people in our study have made remarkable progress given the difficulties of their backgrounds, we cannot foresee whether these successes will last if their current stability in regard to relationships and housing is disrupted. Caitlin's story illustrates how fragile a positive

CDP SPRING 2006 issue article by: KEYS, et al. 
situation may be-like a house of cards, delicately balanced, where moving one may unbalance the whole structure. We can only hope that she is able to rebuild the "normal life" she was so proud to have achieved.

Notes 1. Details of Project i can be obtained from http://www.kcwh.unimelb .edu.au/projecti/

2. Final (2 year) follow-up surveys are currently being completed with these youngpeople.

3. Pseudonyms have been used throughout this paper.

4. See next section for a discussion of what constitutes "problematic use".

References Australian Institute of Health and Welfare (AIHW) (2002) Australia's Health 2002. Canberra: Australian Institute of Health and Welfare.

Ayerst, S.L. (1999) “Depression and stress in street youth". Adolescence 34 (135):567-575

Bailey, S.L., Camlin, C.S. \& Ennett, S.T. (1998) "Substance use and risky behavior among homeless and runaway youth." Journal of Adolescent Health 23:378-388.

Bammer, G. \& Weekes, S. (1994) "Becoming an ex-user: Insights into the process and implications for treatment and policy." Drug \& Alcohol Review 13:285-292.

Bessant, J., Coupland, H.T., Dalton, T., Maher, L., Rowe, J. \& Watts, R. (2002) "Heroin users, housing and social participation: Attacking social exclusion through better housing." Australia: Australian Housing and Urban Research Institute (AHURi) Positioning Paper, Royal Melbourne Institute of Technology (RMIT) Research Centre \& The University of New South Wales (UNSW) - The University of Western Sydney (UWS) Research Centre.

Biernacki, P. (1986) Pathways from Heroin Addiction: Recovery Without Treatment. Philadelphia, PA: Temple University Press.

Blomqvist, J. (1996) "Paths to recovery from substance misuse: Change of lifestyle and the role of treatment." Substance Use and Misuse 31:1807-1852.

Blue Moon Research and Planning (BMR) (2000) "Illicit drugs: Research to aid in the development of strategies to target youth and young people." Canberra, Australia: Commonwealth Department of Health and Aged Care, Population Health Social Marketing Unit.

CDP SPRING 2006 issue article by: KEYS, et al. 
Brown, H. (1991) Report on Services Required for Adolescents with Drugrelated Problems. Melbourne, Australia: Taskforce Community Involvement Centre.

Brady, M. (1993) "Giving away the grog: An ethnography of Aboriginal drinkers who quit without help." Drug \& Alcohol Review 12:402411.

Burrows, C. (1994) Clued up Too: Helping Young People with Drug Issues. Melbourne, Australia: Australian Drug Foundation.

Chen, K. \& Kandel, D.B. (1995) "The natural history of drug use from adolescence to the mid-thirties in a general population sample." American Journal of Public Health 85:41-47.

Coffey, C., Carlin, B., Degenhardt, L., Lynskey, M., Sanci, L. \& Patton, C. (2002) "Cannabis dependence in young adults: An Australian population study." Addiction 97:187-194.

Cunningham, J.A. (1999) "Untreated remissions from drug use: The predominant pathway." Addictive Behaviours 24:267-270.

Cunningham, J.A. (2000) "Remissions from drug dependence: Is treatment a prerequisite?" Drug and Alcohol Dependence 59:211-213.

Cunningham, J.A., Koski-Jännes, A. \& Toneatto, T. (1999) "Why do people stop their drug use? Results from a general population sample." Contemporary Drug Problems 26:695-704.

Department of Human Services. (1998) Young People and Drugs: Needs Analysis. Victoria, Australia: Drug Treatment Services Unit, Aged, Community and Mental Health Division, Department of Human Services.

Di Mascola, E. (1993) Facing the Challenge: A Community Paper on Substance Use Services for Young People in Springvale and Dandenong. Melbourne, Australia: Springvale Community Health Centre.

Downing-Orr, K. (1996) Alienation and social support: A social psychological study of homeless young people in London and Sydney. Alershot, UK: Avebury.

Dowsett, G.W. \& Davis, M. (1998) HIV/AIDS and Collaborative Social Research: A Discussion Paper. Australia: Australian Federation of AIDS Organisations (AFAO).

Duckert, F. (1993) Alcohol Problems and Treatment: Follow-up Studies of Problem Drinkers with Special Reference to Drinking Behaviour. Oslo, Norway: National Institute for Alcohol and Drug Research.

Ennett, S. T., Bailey, S.L. \& Federman, E. B. (1999) “Social network characteristics associated with risky behaviors among runaway and homeless youth." Journal of Health \& Social Behavior 40:63-78.

CDP SPRING 2006 issue article by: KEYS, et al. 
Granfield, R. \& Cloud, W. (1996) "The elephant that no one sees: Natural recovery among middle-class addicts." Journal of Drug Issues 26:45-61.

Granfield, R. \& Cloud, W. (1999) Coming Clean: Overcoming Addiction Without Treatment. New York \& London: New York University Press.

Greenblatt, M. \& Robertson, M.J. (1993) "Lifestyles, adaptive strategies, and sexual behaviours of homeless adolescents". Hospital and Community Psychiatry 44:1167-1187.

Hänninen, V. \& Koski-Jännes, A. (1999) "Narratives of recovery from addictive behaviours." Addiction 94:1837-1848.

Henkel, Y. (1999) “The problem with...” Parity 12(8):3-4.

Klee, H. \& Reid, P. (1998) "Drugs and youth homelessness: Reducing the risk." Drugs Education, Prevention \& Policy 5:269-280.

Koski-Jännes, A. \& Turner, N. (1999) "Factors influencing recovery from different addictions." Addiction Research 7:469-492.

Kral, A.H., Molnar, B.E., Booth, R.E. \& Watters, J.K. (1997) "Prevalence of sexual risk behavior and substance use among runaway and homeless adolescents in San Francisco, Denver and New York." International Journal of STD \& AIDS 8:109-117.

Latkin, C.A., Knowlton, A.R., Hoover, D. \& Mandell, W. (1999) "Drug network characteristics as a predictor of cessation of drug use among adult injection drug users: A prospective study." American Journal of Drug and Alcohol Abuse 25:463-472.

Mallett, S., Edwards, J., Keys, D., Myers, P. \& Rosenthal, D. (2003) Disrupting Stereotypes: Young People, Drug Use and Homelessness. Melbourne, Australia: Key Centre for Women's Health in Society, The University of Melbourne in collaboration with Centre for Community Health, The University of California, Los Angeles.

Mallett, S., Rosenthal, D. \& Keys, D. (2004) "Young people, drug use and family conflicts: Pathways into homelessness". Journal of Adolescence.

McCartney, J. (1996) "A community study of natural change across the addictions." Addiction Research 4:65-83.

Miller, M. \& Draper, G. (2001) Statistics on Drug Use in Australia 2000. Canberra: Australian Institute of health and Welfare.

Moore, D. (1992) “Deconstructing 'dependence': An ethnographic critique of an influential concept.” Contemporary Drug Problems 19:459-490.

Moore, D. (2006) "Beyond 'subculture' in the ethnography of illicit drug use." Contemporary Drug Problems

CDP SPRING 2006 issue article by: KEYS, et al.

07-03-2006 Rev 
Moore, D. (2002) Opening up the cul-de-sac of youth drug studies: A contribution to the construction of some alternative truths. Contemporary Drug Problems 29(1):13-65.

Noble, B. (1999) OK3000 Newly Homeless people: A profile (draft) Melbourne: Melbourne Citimission.

Prochaska, D. \& Di Clemente, C. (1986) "Toward a comprehensive model of change." in Treating Addictive Behaviours: Processes of Change, edited by W. Miller and N. Heather: Plemun Press.

Raynor, K. (2003) Making Change Possible. Adelaide, Australia: Faculty of Health Science, School of Medicine, Department of Public Health, The Flinders University of South Australia.

Ringwalt, C.L., Greene, J.M. \& Robertson, M.J. (1998) "Familial backgrounds and risk behaviors of youth with thrownaway experiences." Journal of Adolescence 21:241-252.

Rosenthal, D., Mallett, S., Milburn, N. \& Rotheram-Borus, M. (2004) "Drug use among homeless young people in Los Angeles and Melbourne." Journal of Adolescent Health.

Sharp, R., Davis, M., Dowsett, G.W., Kippax, S., Hewitt, K., Morgan, S. \& Robertson, W. (1991) Ways of Using: Functional Injecting Drug Users Project. Sydney: Macquarie University, Centre for Applied Social Research.

Smart, R.G., Adlaf, E.M., Walsh, G.W. \& Zdanowicz, Y. (1994) "Similarities in drug use and depression among runaway students and street youth." Canadian Journal of Public Health 85:17-18.

Sobell, L.C., Ellingstad, T.P. \& Sobell, M.B. (2000) "Natural recovery from alcohol and drug problems: methodological review of the research with suggestions for future directions." Addiction 95:749-764.

Unger, J.B. \& Kipke, M.D. (1998) "Stress, coping, and social support among homeless youth." Journal of Adolescent Research 13:134-157.

Waldorf, D. \& Biernacki, P. (1981) "The natural recovery from opiate addiction: Some preliminary findings.” Journal of Drug Issues 11:61-74.

Waldorf, D., Reinarman, C. \& Murphy, S. (1991) Cocaine Changes: The Experience of Using and Quitting. Philadelphia, PA: Temple University Press.

Winick, C. (1962) Maturing out of narcotic addiction. U.S. Bulletin on Narcotics 14.

Whitbeck, L.B. \& Hoyt, D.R. (1999) Nowhere to Grow: Homeless and Runaway Adolescents and their Families. New York, NY: Aldine de Gruyter.

Zinberg, N. (1984) Drug, Set, and Setting. New Haven, CT: Yale University Press.

CDP SPRING 2006 issue article by: KEYS, et al. 

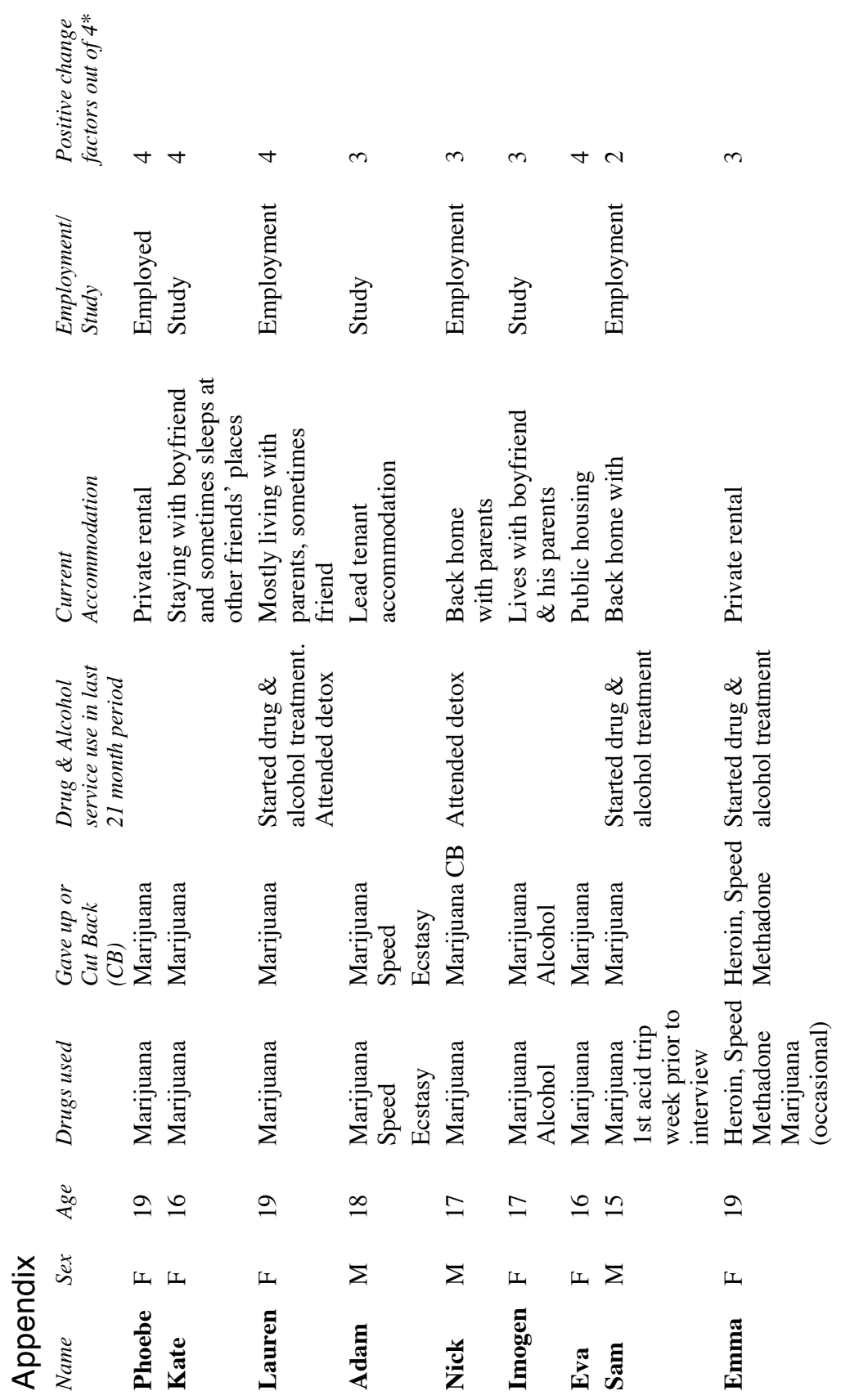


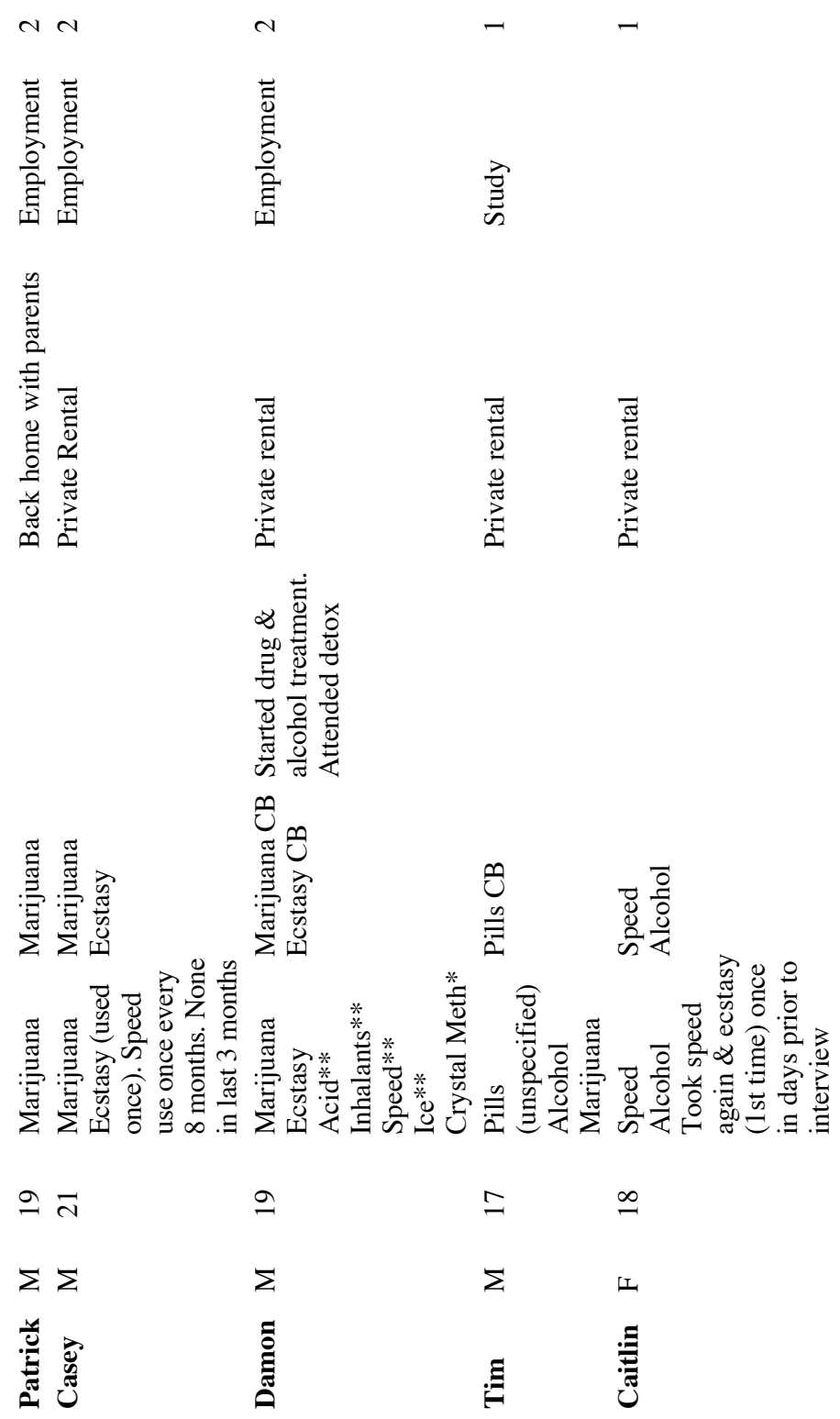

CDP SPRING 2006 issue article by: KEYS, et al. 07-03-2006 Rev 

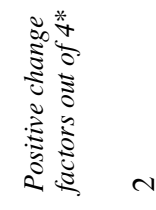

N

क्षे

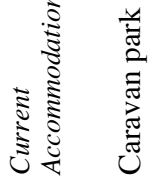

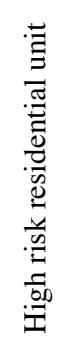

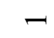

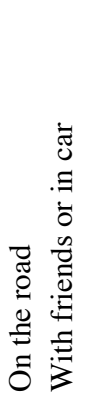

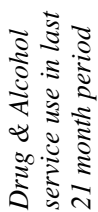

$\bar{\pi}$
$\overline{0}$
$\overline{0}$
$\overline{0}$

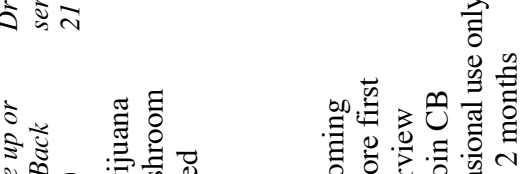

हैं 仓ै
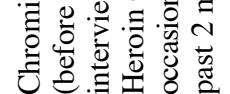

ఫ :

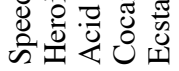
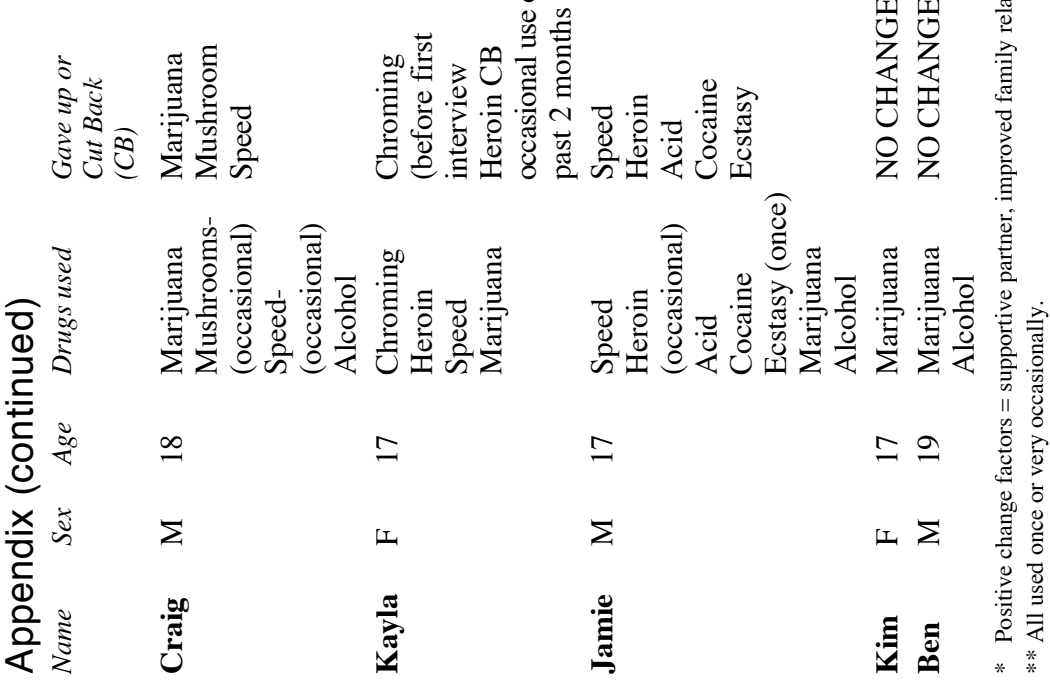

CDP SPRING 2006 issue article by: KEYS, et al. 


\section{University Library}

\section{- M M I N E R VA A gateway to Melbourne's research publications}

Minerva Access is the Institutional Repository of The University of Melbourne

Author/s:

Keys, Deborah;MALLETT, SHELLEY;Rosenthal, Doreen

Title:

Giving up on drugs: homeless young people and self-reported problematic drug use

Date:

2006

Citation:

Keys, D., Mallett, S., \& Rosenthal, D. (2006). Giving up on drugs: homeless young people and self-reported problematic drug use. Contemporary Drug Problems, 33(1), 63-98.

Publication Status:

Published

Persistent Link:

http://hdl.handle.net/11343/34572 